\title{
ПІДГОТОВКА НАУКОВО-ПЕДАГОГІЧНИХ ПРАЦІВНИКІВ У СИСТЕМІ ПІСЛЯДИПЛОМНОї МЕДИЧНОЇ ОСВІТИ ЛІКАРІВ І ПРОВІЗОРІВ НА ОСНОВІ СТРАТЕГІЇ ГІБРИДНОЇ РЕАЛЬНОСТІ
}

\author{
О. П. Мінцер, Л. Ю. Бабінцева \\ Національна медична академія післядипломної освіти імені П. Л. Шупика
}

\begin{abstract}
Представлено новий погляд на питання докорінної зміни викладання в медичних закладах вищої освіти в умовах масового впровадження інформаційних технологій. Підкреслюється, що останнім часом створено принципово нові навчальні середовища, що базуються на включенні як реальних, так і віртуальних об'єктів. Подібні зміни потребують створення нової системи підготовки науково-педагогічних працівників. Тому необхідно обґрунтувати спеціальну класифрікацію знань, що відповідає новим технологічним реаліям навчання в медичних закладах вищої освіти. Зроблено висновки, що питома вага використання розширеної та гібридної реальності поки залишається низькою. Але значна потенційна цінність зазначених технологій для медичної освіти вже найближчим часом може повністю транссормувати медичну освіту, запровадивши навчання на вимогу, віддалений доступ до навчальних матеріалів та об'єктивне оцінювання. Відповідно, вкрай актуальним є першочергова підготовка викладачів у медичних закладах вищої освіти та в системі післядипломної медичної освіти. Важливо також забезпечити відповідний континуум навчання. Запропоновано класифікацію знань, що має викладатися у закладах вищої освіти, особливо в закладах післядипломної освіти. Класифікація представляє собою піраміду знань в основу якої закладаються відносно стабільні стрижневі знання, а на вершині - операційні знання, що постійно змінюються. Комплементарною (перевернутою) пірамідою є питома вага застосування методів віртуальної та гібридної реальності.
\end{abstract}

Ключові слова: гібридна реальність, доповнена реальність, віртуальна реальність, післядипломна медична освіта, підготовка науково-педагогічних працівників, класифікація знань, піраміда знань.

\section{TRAINING OF TEACHERS IN THE SYSTEM OF POSTGRADUATE MEDICAL EDUCATION OF DOCTORS AND PHARMACISTS BASED ON THE HYBRID REALITY STRATEGY}

\author{
O. P. Mintser, L. Yu. Babintseva \\ Shupyk National Medical Academy of Postgraduate Education
}

Background. The issues of radical change of teaching in medical universities in the conditions of mass introduction of information technologies are considered. It is emphasized that recently created fundamentally new learning environments based on the inclusion of both real and virtual objects. Such changes require the creation of a new system of teacher training. The aim of the work was to substantiate a classification of knowledge that corresponds to the new technological realities of education in medical universities.

Materials and methods. Results. It is concluded that the share of the use of augmented and hybrid reality is still low. But the significant potential value of these technologies for medical education in the near future may completely transform medical education, introducing on-demand training, remote access to educational materials and objective assessment. Accordingly, the priority training of teachers in medical universities and in the system of postgraduate medical education is extremely important. It is also important to ensure an appropriate learning continuum.

Conclusions. A classification of knowledge to be taught in higher education, especially in postgraduate medical education, is proposed. It is a pyramid of knowledge based on relatively stable core knowledge, and at the top — constantly changing operational knowledge. The complementary (inverted) pyramid is the share of virtual and hybrid reality methods.

Key words: hybrid reality, augmented reality, virtual reality, postgraduate medical education, teacher training, knowledge classification, knowledge pyramid. 


\title{
ПОДГОТОВКА НАУЧНО-ПЕДАГОГИЧЕСКИХ РАБОТНИКОВ В СИСТЕМЕ ПОСЛЕДИПЛОМНОГО МЕДИЦИНСКОГО ОБРАЗОВАНИЯ ВРАЧЕЙ И ПРОВИЗОРОВ НА ОСНОВЕ СТРАТЕГИИ ГИБРИДНОЙ РЕАЛЬНОСТИ
}

\author{
О. П. Минцер, Л. Ю. Бабинцева
}

Национальная медицинская академия последипломного образования имени П. Л. Шупика

\begin{abstract}
Представлено новый взгляд на вопросы коренного изменения преподавания в медицинских учреждениях высшего образования в условиях массового внедрения информационных технологий. Подчеркивается, что в последнее время созданы принципиально новые учебные среды, основанные на включении как реальных, так и виртуальных объектов. Подобные изменения требуют создания новой системы подготовки научно-педагогических работников. Поэтому необходимо обосновать специальную классификацию знаний, соответствующую новым технологическим реалиям обучения в медицинских вузах. Сделаны выводы, что удельный вес использования расширенной и гибридной реальности остается низким. Но значительная потенциальная ценность указанных технологий для медицинского образования уже в ближайшее время может полностью транссрормировать медицинское образование, введя обучение по требованию, удаленный доступ к учебным материалам и объективное оценивание. Соответственно, крайне актуальным является первоочередная подготовка преподавателей в медицинских вузах и в системе последипломного медицинского образования. Важно также обеспечить соответствующий континуум обучения. Предложена классификация знаний, которая должна преподаваться в вузах, особенно в последипломных учреждениях медицинского образования. Она представляет собой пирамиду знаний, в основу которой закладываются относительно стабильные стержневые знания, а на вершине - операционные знания, постоянно изменяющиеся. Комплементарной (перевернутой) пирамидой является удельный вес применения методов виртуальной и гибридной реальности.
\end{abstract}

Ключевы е слова: гибридная реальность, дополненная реальность, виртуальная реальность, последипломное медицинское образование, подготовка научно-педагогических работников, классификация знаний, пирамида знаний. 
Вступ. Людство розпочало нове життя. Інформаційні технології (IT) практично змінили саме сприйняття об’єктивної реальності. Протягом останніх десятиліть, імітовані навчальні середовища стали дуже складними, включаючи візуальні, звукові, тактильні та рухові компоненти у «віртуальну» реальність [1]. Термін «віртуальна реальність» (BР) означає «... взаємодію між індивідуальним та комп’ютерним середовищем, що стимулює численні сенсорні модальності, включаючи зорові, слухові чи гаптичні переживання» $[3,6,11]$. Останнє середовище моделювання називається доповненою реальністю (ДР), де «віртуальний світ накладається на реальний, тому обидва спостерігаються одночасно» [2]. В деяких роботах розпочато застосування терміну «розширена реальність» (РP, англ. — Extended reality (XR)), що включає ВР, ДР або будь-яку реалізовану комп’ютером реальність [4]. За останнє десятиліття технології розширеної та віртуальної реальності продемонстрували потенціал для трансформації різних сфер. Проте єдиної термінології та єдиної технологічної платформи, на жаль, ще немає. В дослідженні [12] використовується поняття віртуальна реальність як цілком цифрове середовище, не пов'язане з реальним світом і така, що забезпечує повний контроль над зоровим та слуховим досвідом користувача під час їхньої взаємодії у повністю синтетичному середовищі. Розширена реальність дозволяє користувачеві бачити рідне середовище, додаючи до нього доповнені дані. Реальний світ залишається центральним у досвіді, але посилюється віртуальними даними. В об'єднаній реальності або змішаній реальності (3Р) реальний і віртуальний світи переплітаються, це дозволяє взаємодіяти з цифровими об'єктами, зберігаючи відчуття присутності у справжньому фізичному середовищі.

Попит на РР у професіях із високим рівнем ризику, таких як охорона здоров'я, експоненціально зростає через потребу в кваліфікованих операторах і зменшення можливостей для досвіду навчання в реальному світі [2]. Отже, останнім часом створено принципово нові навчальні середовища, що базуються на включенні як реальних, так і віртуальних об’єктів. 3'явилася логіка віртуальної, доповненої та змішаної реальності (остання являє собою щось середнє між віртуальною і доповненою — в буквальному сенсі додає предметам новий вимір) $[1,9,10]$. Віртуальні об'єкти проєктуються на реальний світ таким чином, що кордон між фізичним і цифровим поступово стирається, створюючи єдиний світ незліченних можливостей.
У той же час дослідження, щодо відповідної трансформації навчальних технологій, обгрунтованих комплементарних дидактичних підходів, узгоджених технологій трансферу та трансляції знань поодинокі.

Мета роботи: запропонувати для науково-педагогічних працівників (НПП) безперервного професійного розвитку (БПР) лікарів і провізорів класифікацію видів знань, що відповідає новим технологічним реаліям навчання в медичних закладах вищої освіти (ЗВО).

Результати та їх обговорення. Останнім часом у всьому світі спостерігається зменшення можливостей навчання з реальними пацієнтами. 3 іншого боку постійно підвищується увага та вимоги до результатів діагностики і лікування пацієнтів, у тому числі, в форматі віддаленого доступу до них. Одним із наслідків подібних «ножиць завдань» $€$ зростання попиту на більш просунуті методи моделювання, в першу чергу, розширеної (віртуальної, доповненої або змішаної) реальності протягом усього континууму медичної освіти, особливо в системі безперервного професійного розвитку лікарів і провізорів. Підкреслимо, що попит на РР у професіях із високим ризиком, таких як охорона здоров'я, збільшився у геометричній прогресії через потребу в кваліфікованих операторах і зменшення можливостей для практичного навчання [1, 2]. Наприклад, використовуючи ДР лікарі можуть інтегрувати цифрові біомедичні дані комп’ютерної томографії.

Зауважимо, що технології РР, ВР, ДР тощо - це не просто навчальний інструмент для студентівмедиків або в системі безперервного професійного розвитку. Зазначені технології також можна використовувати для оцінювання знань. Останнє пояснюється тим, що стандартизовані тести, які широко застосовуються як у додипломній освіті, так i в післядипломній можуть лише з відносною точністю продемонструвати засвоєння клінічної інформації, але цей спосіб оцінювання обмежений двома факторами. По-перше, він не встигає за швидкими змінами контенту освіти, а по-друге, він не віддзеркалює логіку міркувань при формуванні відповіді. Технології віртуальної реальності можуть допомогти суб' єктам навчання та викладачам поступово прогресувати шляхом «повторного тестування, зворотного зв'язку та самоконтролюючої практики» [6]. РР також може забезпечити значні успіхи в оцінюванні процедурних навиків суб'єктів навчання. Якщо НПП використовували рентгенівське моделювання пацієнтів і хірургічне моделювання 
для оцінювання суб’єктів навчання, вони могли б стандартизувати отримані оцінки, роблячи таким чином оцінювання знань об’єктивнішим, точнішим і справедливішим. Підкреслюється, що «ітеративний дизайн допомагає забезпечувати формальні оцінки ... системи, генерувати зворотний зв’язок щодо процесу та розробляти нові, вдосконалені версії для подальшого тестування» [1].

Інновації у медичній освіті стикаються з безліччю проблем. Одна з найбільших - несприйняття більшістю викладачів і лікарів, стійких до зміни свого підходу до викладання медицини. Відповідно першим кроком до впровадження нового навчального інструменту, такого як РP, є спеціальна підготовка НПП. Зауважимо, що введення нового способу навчання у традиційний навчальний план вимагає мультидисциплінарного підходу. Клініцисти надають медичну експертизу та адміністративну структуру, але потребують технічних навиків інженерів, знань викладачів щодо принципів навчання та розроблення навчальних програм, а також готовності лікарів використовувати нові технології для створення життєздатного пілотного проєкту. Необхідність мультидисциплінарної співпраці поширюється й за стіни медичного закладу. Викладачі післядипломної освіти, які володіють глибоким досвідом у використанні новітніх інформаційних технологій потребують спільної роботи із зовнішніми чи внутрішніми компаніями, щоб визначити, протестувати, продемонструвати докази ефективності та врешті-решт співпрацювати у впровадженні нових технологій освіти.

Хоча технологія ДР має потенціал покращити або замінити деякі традиційні методи медичного навчання, численні систематичні огляди не наводять переконливих оцінок обгрунтованості ДР. Незважаючи на ці недоліки, у багатьох дослідженнях встановлено позитивні відповіді на ДР та бажання як слухачів, так і експертів бачити технологію, впроваджену в навчальних програмах. Проте, такі висновки підкреслюють зростаючу актуальність і зацікавленість споживачів у застосуванні моделювання ДР у медичній освіті [12].

Нам здається, що основні причини невпевнених результатів застосування технологій ДР, РР та інших пов’язані з неправильною попередньою класифікацією знань, що виділяються для навчання. Досвід авторів надає можливість рекомендувати для контактного передавання знань відносно невеликі, але важливі базисні знання. В наших дослідженнях вони отримали назву стрижневих знань. За попередніми роботами їх обсяг не перевищує 15-20\%. Використання сучасних інформаційних технологій, навпаки, мінімальне.
Розширення спектру знань обумовлює зниження питомої ваги класичних методів передавання знань i, навпаки, розширення підходів, пов' язаних із ВР, ДР, РР тощо. Іншими словами, створюються дві усічені піраміди - одна відображає поступове зниження питомої ваги застосування контактних методів у міру розвитку навчального процесу. Друга піраміда має вигляд перевернутої усіченої піраміди. Вона віддзеркалює зворотній процес - поступового збільшення питомої ваги нових інформаційних технологій, що на заключному етапі навчання займають практично всі 100 \%.

Отже, застосування технологій ДР, РР та інших у медичній освіті знаходиться на ранніх стадіях. Більш того, в даний час їм бракує підтримки, заснованої на доказах, для широкого впровадження. Майбутні дослідження повинні використати довгострокові та масштабні проєкти або когортні дослідження відповідно до запропонованої моделі для оцінювання ефективності ДР, РР. Стандартизована перевірка комерційно життєздатних додатків дозволить переліченим технологіям легше інтегруватись у медичні навчальні програми.

Хоча технології ДР швидко зростають, нинішня якість і масштаби досліджень ДР у медичній підготовці є недостатніми для того, щоб рекомендувати їхнє прийняття до навчальних програм. Але автори сподіваються, що стандартизація методів застосування технологій ВР, РР, ДР визначить їхню роль у медичній освіті.

Висновки. 1. Питома вага використання розширеної та гібридної реальності поки залишається низькою. Але значна потенційна цінність зазначених технологій для медичної освіти вже найближчим часом може повністю трансформувати медичну освіту, запровадивши навчання на вимогу, віддалений доступ до навчальних матеріалів і об'єктивне оцінювання. Відповідно, вкрай актуальною стає першочергова підготовка викладачів у медичних ЗВО та в системі післядипломної медичної освіти. Важливо також забезпечити відповідний континуум навчання.

2. Запропоновано класифікацію знань, що має викладатися у 3ВО, особливо на післядипломному етапі. Вона представляє собою піраміду знань в основу якої закладаються відносно стабільні стрижневі знання, а на вершині - операційні знання, що постійно змінюються. Комплементарною (перевернутою) пірамідою є питома вага застосування методів віртуальної та гібридної реальності. 


\section{Література.}

1. Extended Reality in Medical Education: Driving Adoption through Provider Centered Design / Zweifach S. M., Triola M. M. // Digit Biomark. - 2019. — Vol. 3, No. 1. - P. 14-21.

2. See one, do one, teach one: advanced technology in medical education / Vozenilek J., Huff J. S., Reznek M., Gordon J. A. // Acad Emerg Med. - 2004. № 11 (11). — P. 1149-1154.

3. Virtual reality and medical inpatients: a systematic review of randomized, controlled trials / Dascal J., Reid M,. Ishak W. W. et al. // Innov Clin Neurosci. —2017. — № 14 (1-2). — P. 14-21.

4. Mixed objective-virtual reality: theoretical analysis of basic characteristics of modern education / Yachina N., Zeynalov G., Dyushebekova G. Z. // Math Educ. 2016. — № 11 (1). — P. 271-278.

5. A meta-analysis of anatomy laboratory pedagogies / Wilson A. B., Miller C. H., Klein B. A. et al. // Clin Anat. — 2018. — № 31 (1)/ — P. 122-133.

6. Stanford Medicine, Neurosurgery. Stanford Neurosurgical Simulation and Virtual Reality Center. 2019 [cited 2019 Jan 29]. — Режим доступу: http://med.stanford.edu/ neurosurgery/divisions/vr-lab.html.

7. Virtual reality-based medical training and assessment: the multidisciplinary relationship between clinicians, educators and developers / Lövquist E., Shorten G., Aboulafia A. // Med Teach. — 2012. — № 34 (1). — P. 59-64.

8. Accelerating change: fostering innovation in healthcare delivery at academic medical centers / Ostrovsky A., Barnett M. // Healthc (Amst). — 2014. — № 2 (1). — P. 9-13.

9. Mixed reality: a revolutionary breakthrough in teaching and learning / Workman S. B. // EDUCAUSE Rev. - 2018. - Режим доступу: https://er.educause. edu/articles/2018/7/mixed-reality-a-revolutionarybreakthrough-in-teaching-and-learning.

10. Virtual and augmented reality in medical education / Pantelidis P., Chorti A., Papagiouvanni I. et al. In: Medical and surgical education — past, present and future. - London: IntechOpen, 2018. — Режим доступу: https://www.intechopen.com/books/medicaland-surgical-education-past-present-and-future/virtualand-augmented-reality-in-medical-education.

11. University of Illinois Helps Develop Revolutionary Virtual Reality for Learning. - 2019. — Режим доступу: http://www.govtech.com/education/higher-ed/ University-of-Illinois-Helps-Develop-RevolutionaryVirtual-Reality-for-Learning.html.

12. Augmented reality in medical education: a systematic review / K. S. Tang, D. L. Cheng, E. Mi, P. B. Greenberg // Canadian Medical Education Journal. — 2020. — № 11 (1). — P. e81-e96.

\section{References.}

1. Zweifach S. M., Triola M. M. (2019). Extended Reality in Medical Education: Driving Adoption through Provider Centered Design. Digit Biomark, 3, 1. doi. org/10.1159/000498923.

2. Vozenilek J., Huff J. S., Reznek M., Gordon J. A. (2004). See one, do one, teach one: advanced technology in medical education. Acad Emerg Med., 11 (11),1149-54.

3. Dascal J., Reid M., Ishak W. W. et al. (2017). Virtual reality and medical inpatients: a systematic review of randomized, controlled trials. Innov Clin Neurosci., 14 (1-2), 14-21.

4. Yachina N., Zeynalov G., Dyushebekova G. Z. (2016). Mixed objective-virtual reality: theoretical analysis of basic characteristics of modern education. Math Educ., 11 (1), 271-8.

5. Wilson A. B., Miller C. H., Klein B. A. et al. (2018). A meta-analysis of anatomy laboratory pedagogies. Clin Anat., 31 (1), 122-33.

6. Stanford Medicine, Neurosurgery. Stanford Neurosurgical Simulation and Virtual Reality Center (2019) [cited 2019 Jan 29]. Available from: http://med.stanford.edu/ neurosurgery/divisions/vr-lab.html.

7. Lövquist E, Shorten G, Aboulafia A. (2012). Virtual reality-based medical training and assessment: the multidisciplinary relationship between clinicians, educators and developers. Med Teach., 34 (1), 59-64.

8. Ostrovsky A., Barnett M. (2014). Accelerating change: fostering innovation in healthcare delivery at academic medical centers. Healthc (Amst)., 2 (1), 9-13.

9. Workman S. (2018). Mixed reality: a revolutionary breakthrough in teaching and learning. EDUCAUSE Rev. Available from: https://er.educause.edu/articles/ 2018/7/mixed-reality-a-revolutionary-breakthrough-inteaching-and-learning.

10. Pantelidis P., Chorti A., Papagiouvanni I. et al. (2018). Virtual and augmented reality in medical education. In: Tsoulfas G, editor. Medical and surgical education - past, present and future. London: IntechOpen. doi:10.5772/ intechopen.71963. Available from: https://www. intechopen.com/books/medical-and-surgical-educationpast-present-and-future/virtual-and-augmented-realityin-medical-education.

11. University of Illinois Helps Develop Revolutionary Virtual Reality for Learning (2019). Available from: http://www.govtech.com/education/higher-ed/ University-of-Illinois-Helps-Develop-RevolutionaryVirtual-Reality-for-Learning.html.

12. Tang K. S., Cheng D. L., Mi E., Greenberg P. B. (2020). Augmented reality in medical education: a systematic review. Canadian Medical Education Journal, 11 (1), e81-e96. 